J. Dairy Sci. 92:4347-4354

doi:10.3168/jds.2009-2051

(c) American Dairy Science Association, 2009.

\title{
Chlamydophila species in dairy farms: Polymerase chain reaction prevalence, disease association, and risk factors identified in a cross-sectional study in western Germany
}

\author{
K. Kemmerling, U. Müller, ${ }^{1}$ M. Mielenz, and H. Sauerwein \\ Institute of Animal Science, Physiology and Hygiene Group, University of Bonn, D-53115 Bonn, Germany
}

\begin{abstract}
The prevalence of Chlamydophila spp. was determined in a cross-sectional study carried out in 2007 using 100 randomly selected dairy herds in the western part of Germany. Ten dairy cows per herd were sampled in herds with fewer than 100 cows; in bigger herds, 10\% of the cows were sampled. For the detection of Chlamydophila spp., vaginal swabs from early lactating dairy cows were analyzed using an established highly sensitive genus-specific real-time PCR. In consideration of the discontinuous shedding of the pathogen, a herd was classified as positive if at least 1 animal per herd tested positive for Chlamydophila spp. By use of these methods and definitions, $61 \%$ of the dairy herds and $13.5 \%$ of the cows were detected as PCR-positive for Chlamydophila spp., which is indicative for ongoing infections. To compare herd health and herd performance between herds testing positive or negative and to identify risk factors for the presence of Chlamydophila spp., a questionnaire was designed to evaluate farm characteristics and management practices. In addition, the performance recordings of the state dairy recording organization were used for these purposes. Milk yield, number of lactations, and calving to first-service interval were lower in herds testing positive for Chlamydophila spp. compared with negative herds. For all these variables, there was no interaction between Chlamydophila status and lactation number. Replacement of animals from outside sources, use of breeding bulls, lack of separate calving pens, and low scores for cleanliness of beddings, walkways, and cows were identified as the main risk factors for Chlamydophila spp.
\end{abstract}

Key words: Chlamydophila spp., dairy farm, prevalence, risk factor

Received January 20, 2009.

Accepted May 4, 2009.

${ }^{1}$ Corresponding author: ute-mueller@uni-bonn.de

\section{INTRODUCTION}

Bacteria belonging to the genus Chlamydophila are of considerable importance to both human and animal health. In addition to Chlamydophila psittaci causing avian chlamydiosis, which is the most important animal chlamydiosis transmissible to man, the species identified in ruminant livestock species (mainly Chlamydophila abortus and Chlamydophila pecorum) are also of some zoonotic relevance (Longbottom and Coulter, 2003). Chlamydial infections in cattle cause a range of clinical conditions such as pneumonia, polyarthritis, conjunctivitis, abortion, endometritis, and impaired fertility (Wilson and Thompsen, 1968; Wittenbrink et al., 1988).

Several investigations report a high prevalence of antibodies against Chlamydophila spp. in cattle that is linked to increased prevalence of endometritis, fertility disorders, and epizootic bovine abortion (Wittenbrink et al., 1988; Domeika et al., 1994; Cavirani et al., 2001; Wang et al., 2001; Wehrend et al., 2005). However, seroprevalence may not reflect the actual presence of the antigen in a given population. High seroprevalence, approaching 100\%, and chlamydial genomic DNA prevalence as high as 50 to $60 \%$ has been associated with clinically inapparent bovine infection with Chlamydophila spp. (Domeika et al., 1994; Kaltenboeck et al., 1997a; Cavirani et al., 2001; Wang et al., 2001; DeGraves et al., 2003; Jee et al., 2004). Most of the studies on the prevalence of Chlamydophila spp. infections in dairy cattle, diagnosed via specific antibody titer tests or by assaying the specific nucleic acid by PCR, are limited to subpopulations that were preselected for an increased occurrence of disorders commonly linked to the infection. Thus, our first aim was to evaluate the actual prevalence of Chlamydophila spp. in the entire dairy cow population of our region - the western part of Germany (North Rhine-Westphalia, NRW) - using a truly randomized cross section regardless of any healthrelated preinformation. In addition, we focused our study to the detection of Chlamydophila spp. applying a highly sensitive quantitative real-time PCR protocol and thus recording ongoing infections. 
Chlamydophila spp. can be shed in feces, in vulvar, ocular, and nasal discharges, uterine fluids, placental membranes, urine, and semen (Perez-Martinez and Storz, 1985; Rodalkis et al., 1998; Longbottom and Coulter, 2003). Transmission routes can be fecal-oral, by inhalation of contaminated air (oronasal) and veneral (Schachter et al., 1975; Gerbermann, 1991; Papp and Shewen, 1996; Rodalkis et al., 1998; Longbottom and Coulter, 2003) and thus offer a range of possibilities for infection and dispersion for Chlamydophila spp. Our second aim was to compare herd performance and reproductive health between herds with or without positive Chlamydophila spp. tests. Finally, in consideration of the transmission routes, we aimed to identify risk factors.

\section{MATERIALS AND METHODS}

\section{Study Design}

In this cross-sectional study, 100 dairy farms were randomly selected in NRW. In this state, $10 \%$ of Germany's total milk is produced in 6,557 dairy farms with, in total, 315,855 dairy cows (Arbeitsgemeinschaft Deutscher Rinderzuechter, 2006) in NRW. To obtain a random sample of 100 dairy farms, the dairy cow stocking rate in the different administrative districts of NRW $(\mathrm{n}=32)$ was taken into account. If, for example, $5 \%$ of the cows in total NRW are kept in one particular district, 5 randomly selected farms of this district would have been sampled with at least 10 cows per farm. The portion of the total cow population in the different districts ranged from 0.23 to $12.4 \%$. In herds with fewer than 100 cows, 10 cows were sampled; in herds with more than 100 cows, $10 \%$ of the cows were sampled. The total number of cows tested in this study was 1,074 . In consideration of the discontinuous shedding of the pathogen (Jee et al., 2004; Reinhold et al., 2008) and of the fact that Cp. abortus and Cp. pecorum are endemic at low levels in cattle and infect virtually $100 \%$ of the animals (Kaltenboeck et al., 2005), a farm was classified as positive in this study if at least one animal per farm tested positive for an ongoing infection with Chlamydophila spp.

We aimed to sample nonpregnant, early lactating dairy cows $(<100$ DIM) because the metabolic stress of early lactation may lead to immunosuppression and thus to an increased susceptibility for diseases (Goff and Horst, 1997). In case of insufficient numbers of cows with fewer than 100 DIM per farm, cows of later lactational stages were sampled. On average, cows were sampled at 72 DIM ( 1 to $289, \mathrm{SD}=55$ ).

\section{Data Collection}

On the day of sample collection, each farmer was interviewed using a questionnaire about the following farm characteristics, aspects of management, and milk performance recording data from the last 12 mo. In addition, the interviewer visited the barns and milking parlors to get an overall impression of the general housing and management conditions and the animals.

1) Milk performance recording data of the 100 dairy herds sampled (provided for each individual cow by the state milk recording system in NRW (Landeskontrollverband, LKV) with 11 recordings per year): milk yield, milk composition (fat and protein content, SCC), and numbers of lactation. The 12-mo rolling averages, monthly herd performance, and milk recording data were updated monthly.

2) Reproductive data (also provided by LKV NRW): services per conception, calving to firstservice interval, calving to conception interval, and culling rate.

3) Calving data (data from management programs): preterm or late calving, dystocia, medical treatments postpartum, twin births, abortion, perinatal death, and retained placenta.

4) General housing and management conditions (questionnaire and observation data): barns, lying areas, bedding, cleaning of various functional areas and bedding, availability of separate calving pens, replacement heifers from outside or inside sources, and artificial insemination or bull breeding.

5) Gross appearance of the dairy cows (observation data, acquired by the interviewer): feet and legs, general cleanliness, vaginal cleanliness, and occurrence of lesions.

The median number of animals per herd was 78 (range: 34 to 346 ), and the average milk yield from all herds per year was $8,882 \mathrm{~kg}$ of milk $(7,326$ to 11,373 $\mathrm{kg}, \mathrm{SD}=825 \mathrm{~kg})$ with $4.24 \%$ fat $(3.57$ to $4.71 \%, \mathrm{SD}=$ 0.23 ) and $3.33 \%$ protein (3.02 to $3.61 \%, \mathrm{SD}=0.12$ ). All performance data are averages from entire herds and were summarized from the annual milk performance data recorded by the LKV.

\section{Collection and Processing of Samples and Detection of Chlamydophila spp. by Real-Time PCR}

Vaginal mucus was collected with a cotton swab (Salivette, Sarstedt, Nümbrecht, Germany) from each 
cow sampled, kept at $4^{\circ} \mathrm{C}$, and processed on the next day. Vaginal swabs were used because the detection rates of Chlamydophila spp. are reportedly higher in this medium compared with other body fluids (Jee et al., 2004). Swabs were prepared as described by Hotzel et al. (1996) with minor modifications (i.e., using $1.2 \mathrm{~mL}$ of the lysis buffer). The cotton swabs were centrifuged at $2,500 \times g$ for $30 \mathrm{~s}$ at $4^{\circ} \mathrm{C}$. The liquid obtained was then centrifuged at $17,530 \times g$ for $15 \mathrm{~min}$ at $4^{\circ} \mathrm{C}$, and the pellet was redissolved in approximately twice the volume of isopropanol and incubated overnight. After a further short centrifugation, the tubes were drained and left standing inverted for $2 \mathrm{~min}$; then, the pellet was dissolved in $20 \mu \mathrm{L}$ of ultra-pure $\mathrm{H}_{2} \mathrm{O}$ and stored at $-20^{\circ} \mathrm{C}$.

A quantitative real-time $\mathrm{PCR}$ was performed to detect Chlamydophila genomic $23 \mathrm{~S}$ rRNA as described by Borel et al. (2008) in their comparison of different PCR tests with DNA microarray testing, except that we used $2 \mu \mathrm{L}$ of the sample DNA template instead of $1 \mu \mathrm{L}$. In brief, $23 \mu \mathrm{L}$ of a master reaction mix containing $12.5 \mu \mathrm{L}$ of qPCR Master Mix (RT-QP2x-03NR), $4.5 \mu \mathrm{L}$ of the forward primer Ch23S-F (5'CTG AAA CCA GTA GCT TAT AAG CGG T $\left.3^{\prime}\right), 4.5 \mu \mathrm{L}$ reverse primer Ch23S-R (5'ACC TCG CCG TTT AAC TTA ACT CC $\left.3^{\prime}\right), 0.5 \mu \mathrm{L}$ of ultra-pure $\mathrm{H}_{2} \mathrm{O}$, and $1 \mu \mathrm{L}$ of the probe (tippelt, 5'FAM 3'TAMRA) Ch23S (5'FAM CG GCG TGC CTT TTG CAT GAT GAG 3'TAMRA) were added. All PCR materials were from Eurogentec (Brussels, Belgium); the cycler (Mx 3000P) was from Stratagene (Amsterdam, the Netherlands). Decadic dilution series from $10^{4}$ to $10^{-1}$ copies of a mixture of $C p$. psittaci DC 14, Cp. pneumoniae DC 40, Cp. pecorum DC 47, and Chlamydia trachomatis DC 10 standards (Federal Institute for Animal Health, Jena, Germany) were used as reference. Ultra-pure $\mathrm{H}_{2} \mathrm{O}$ instead of sample DNA was used as negative control. Using Bayesian techniques to estimate the diagnostic performance, a sensitivity of 0.9 (median, with $95 \%$ credible intervals between 0.83 and 0.96 ) was defined for the real-time PCR used herein (Borel et al., 2008). The detection limit of this real-time PCR was determined to be 56 copies, equivalent to $0.05 \mathrm{fg}$ of DNA (Ehricht et al., 2006).

\section{Identification of Chlamydophila spp.}

In case of positive findings, the Chlamydophila species involved were specified in a nested PCR using the sample DNA. Variable domains III and IV of the Chlamydophila ompA gene were targeted using a modified version (primer CHOMP336s; Sachse and Hotzel, 2003) of the nested PCR procedure originally described by Kaltenboeck et al. (1997b). In the first round, $5 \mu \mathrm{L}$ of DNA extract was amplified using the primer pair 191CHOMP/CHOMP371. Subsequently, $1 \mu \mathrm{L}$ of the PCR product served as template in the second round, which used primer pair 201CHOMP/TRACH269 (Chlamydia trachomatis), 201CHOMP/PNEUM268 ( $C p$. pneumonia), 204PECOR/CHOMP336s (Cp. pecorum), or 218PSITT/CHOMP336 ( $C p$. psittaci/Cp. abortus). All primers were from Eurogentec; DNA Polymerase (SupraTherm) and $10 \times$ reaction buffer were from GeneCraft (Köln, Germany); dNTP mixture, gel loading buffer, and DNA size marker were from Fermentas (St. Leon-Roth, Germany). To discriminate between $C p$. abortus and $C p$. psittaci, a PCR according to Laroucau et al. (2001), as modified by Laroucau et al. (2007), was used. The PCR materials were the same as in the nested PCR, except that the primers were from Sigma-Aldrich (Taufkirchen, Germany). All PCR amplifications were run with positive controls $(C p$. psittaci DC 14, Cp. pneumoniae DC 40, Cp. pecorum DC 47, and Chlamydia trachomatis DC 10) and 2 negative controls (ultra-pure $\mathrm{H}_{2} \mathrm{O}$ ). The reaction products from the positive and the negative controls in the first-round nested PCR were additionally subjected to the second nested PCR. All PCR products obtained were evaluated by electrophoresis.

\section{Data Analysis}

Data were analyzed using the statistical software package SPSS 15.0 (SPSS Inc., Chicago, IL) to find differences between farms with positive and negative testing of Chlamydophila spp. Within the variables, performance data associated with the presence of Chlamydophila spp. in a herd were differentiated from risk factors being causally related to transmission or infection. All performance data as quantitative variables were analyzed by Student-Fisher $t$-tests to identify potential relationships to the Chlamydophila spp. classification in a herd (considering the homogeneity of variance by using the Levene test). In addition, the average lactation number per herd (as lactation groups) was evaluated in a 2-way ANOVA by taking Chlamydophila classification (CC) and the lactation groups (LaGr) as fixed effects (considering the homogeneity of variance by using the Levene test, the normal distribution by Shapiro-Wilk test) into account:

$$
\mathrm{y}_{\mathrm{ij}}=\mu+\mathrm{CC}_{\mathrm{i}}+\mathrm{LaGr}_{\mathrm{j}}+(\mathrm{CC} \times \mathrm{LaGr})_{\mathrm{ij}}+\mathrm{e}_{\mathrm{ij}},
$$

where $\mathrm{CC}=$ Chlamydophila spp. classification (positive, negative), $\mathrm{LaGr}=$ lactation group, with $\mathrm{i}=0,1(0$ $=$ negative testing for Chlamydophila spp., $1=$ positive testing for Chlamydophila spp.) and $\mathrm{j}=1,2,3(1=\mathrm{LaGr}$ $<2.0,2=$ LaGr 2.0-2.9, $3=\mathrm{LaGr} \geq 3.0$ ). 
Homogeneity of variance and normal distribution were confirmed. Statistical significance was indicated by $P<0.05$.

Categorical variables describing the conditions at the farms (calving data, general housing and management conditions, appearance of the cows) were compared by $\chi^{2}$ tests to identify potential relations with the Chlamydophila spp. classification under automatic consideration of routines for cross tables with frequencies $<5 \%$ $(P<0.05)$.

For the identification of risk factors, odds ratios (OR) or risk ratios (RR) with their 95\% corresponding confidence intervals (CI) were calculated. Presentation of the results is limited to those variables for which significant differences were detectable between positive and negative herds (by $P<0.05$ ) and that had a lower limit of CI $>1.0$.

\section{RESULTS AND DISCUSSION}

\section{Prevalence}

Chlamydophila spp. were detected in $61 \%$ of 100 randomly selected dairy farms in NRW, equivalent to $13.5 \%$ of the 1,074 sampled cows. The PCR diagnosis used herein is limited to those animals and herds that undergo a current infection at the time of sampling. In contrast to serology, the overall presence or exposure toward Chlamydophila spp. on the farm cannot be identified. Because of the discontinuous shedding of the pathogen (Jee et al., 2004; Reinhold et al., 2008), the actual prevalence of ongoing infections with Chlamydophila spp. might have been higher because some animals might have been classified as false negative. The quantitative real-time PCR used herein for Chlamydophila detection is 10 to 100 times more sensitive than the nested PCR (Helps et al., 2001). For this reason, species identification was successful in only 95 cases of 145 positive findings. The most prevalent species found was $C p$. psittaci (55.8\%), followed by $C p$. abortus (35.8\%); Cp. pecorum was observed in only $8.4 \%$ of these samples. Occurrence of $C p$. psittaci in cattle has been reported previously, for example, in Switzerland (Borel et al., 2006). The overall prevalence of Chlamydophila spp. observed herein is slightly higher than that previously reported for Austria (Petit et al., 2008). In that study, 644 animals from 196 farms in Austria were sampled via vaginal or cervical swabs and analyzed by PCR followed by RFLP analysis. Using this analysis, only $C p$. abortus and $C p$. pecorum were detectable. In the Austrian study, $C p$. abortus was not found and a prevalence of $8.9 \%$ was observed for Cp. pecorum. These numbers are related to the animals and provide no information about the percentage of the herds in which positive cases were found. Because of the different analytical methods used, a direct comparison with our results is not possible. Nevertheless, the Austrian study (Petit et al., 2008) and the current study are, to our knowledge, the only ones that used a true random sample and not preselected herds for PCR detection of Chlamydophila spp. In contrast, seroprevalences are reported for several countries using both preselected and randomly selected herds: in European herds preselected for their increased rate of fertility disorders or abortion rate, seroprevalences of $91 \%$ (Germany, 89 herds; Sting, 1997), $81 \%$ (Sweden, 70 herds; Godin et al., 2008), and $54 \%$ (Germany, 59 herds; Wittenbrink et al., 1988), respectively, are reported. In an Asian study (Taiwan), $100 \%$ seroprevalence has been documented (72 herds; Wang et al., 2001). Studies using randomly selected farms report 90\% (20 herds, Germany; Abd El-Rahim, 2002) and 44.9\% (196 herds, Austria; Petit et al., 2008) of the cows being seropositive. Taken together, the data available indicate that Chlamydophila spp. are highly prevalent in cattle and thus confirm earlier valuations (Shewen, 1980; Jee et al., 2004).

\section{Chlamydophila PCR Status: Herd Performance and Farm Conditions}

Data from Milk Recordings. The milk performance recordings of the herds classified as either positive or negative for Chlamydophila spp. are presented in Table 1. Milk yield, number of lactations, time intervals from calving to first service and from calving to conception were greater $(P<0.05)$ in herds classified as being free of Chlamydophila spp., whereas no differences were detectable for the other variables investigated. Considering that the differences observed might be related to lactation number rather than CC, we performed supplementary statistics taking the effects of lactation number into account and thereby confirmed the effect of the CC on milk yield and calving to first-service interval. No interaction between $\mathrm{CC}$ and $\mathrm{LaGr}$ was identified for any variable tested. The observation of a reduced interval from calving to first service in herds with positive CC was unexpected because Chlamydophila infections are reportedly related to reduced fertility in dairy cows (Sting, 1997; DeGraves et al., 2003; Wehrend et al., 2005). This divergence might be attributable to the relatively lower milk yield in positive herds. Cows with lower milk yield are often bred earlier than high-yielding dairy cows; in addition, high-yielding cows often have longer calving to conception intervals than cows with lower milk yields (Lee et al., 1997). In addition to CC, lactation number was significant for the calving to firstservice interval. For the calving to conception interval for which no $\mathrm{CC}$ related differences were observed in 
Table 1. Comparison of milk performance data in herds classified as positive or negative (mean \pm SD) for the presence of Chlamydophila spp. in a study of 100 dairy herds randomly selected in 2007 in western Germany

\begin{tabular}{|c|c|c|c|c|c|c|}
\hline Variable & $\begin{array}{l}\text { Positive }^{1} \text { herds } \\
\quad(\mathrm{n}=61)\end{array}$ & $\begin{array}{l}\text { Negative }^{1} \text { herds } \\
\quad(\mathrm{n}=39)\end{array}$ & $\begin{array}{c}P \text {-value }{ }^{2} \\
\text { from the } t \text {-test }\end{array}$ & \multicolumn{3}{|c|}{$P$-value from 2 -way ANOVA $^{2}$} \\
\hline Milk yield/yr $(\mathrm{kg})$ & $8,681 \pm 793$ & $9,197 \pm 786$ & 0.002 & 0.012 & 0.126 & NS \\
\hline Fat content $(\%)$ & $4.24 \pm 0.23$ & $4.24 \pm 0.09$ & 0.967 & & & \\
\hline Protein content (\%) & $3.33 \pm 0.14$ & $3.34 \pm 0.09$ & 0.792 & & & \\
\hline Log SCC & $5.32 \pm 0.13$ & $5.38 \pm 0.17$ & 0.48 & & & \\
\hline Services per conception $(\mathrm{n})$ & $1.9 \pm 0.27$ & $2.0 \pm 0.30$ & 0.30 & & & \\
\hline Calving to first-service interval (d) & $91 \pm 12$ & $100 \pm 11$ & $<0.001$ & 0.021 & $<0.001$ & NS \\
\hline Calving to conception interval (d) & $126 \pm 17$ & $136 \pm 17$ & 0.006 & 0.085 & $<0.001$ & NS \\
\hline
\end{tabular}

${ }^{1} \mathrm{~A}$ farm was classified as positive if at least one animal per farm was tested positive for Chlamydophila spp.

${ }^{2}$ Significance, $P<0.05$; the variables were first compared by Student-Fisher $t$-tests. In addition, to dissect potential autocorrelations, the average lactation number per herd was co-evaluated in a 2-way ANOVA by taking the Chlamydophila classification (CC) and the lactation number into account. For the latter, lactation groups (LaGr) were formed: LaGr $1=$ average herd lactation number $<2.0$ (n=11 herds), LaGr $2=$ average herd lactation number between 2.0 and $2.9(\mathrm{n}=64$ herds), and LaGr $3=$ average herd lactation number $>3.0(\mathrm{n}=25$ herds).

the model considering lactation number, only the latter was significant. Again, this might be explained by the relatively higher milk yield of older cows with accordingly later breeding time.

Pregnancy Outcome and Calf Mortality. The occurrence of abortion and preterm calvings, the frequency of perinatal losses, and health disturbances of dam and offspring are possibly related to Chlamydophila spp. Table 2 presents those variables for which a significant relationship with Chlamydophila status was observed. To calculate the RR of abortions, preterm calving, and perinatal deaths, 2 frequency classes were formed in the following analyses: $<2 \%$ and $\geq 2 \%$. The risk of being infected with Chlamydophila spp. for a dairy herd was 2.9-fold higher (CI: 2.3-10.2) if more than $2 \%$ abortions occurred, 3.3-fold higher (CI: $1.9-5.9$ ) if more than $2 \%$ preterm calving, and 3.0-fold higher (CI: 1.8-5.0) if more than $2 \%$ perinatal deaths occurred, respectively.

It is known that Chlamydophila spp. may locally affect placental function and may thus lead to abortion or perinatal death (Buxton et al., 1990). Our data confirm this relationship, showing increased rates of abortion, preterm calvings, and perinatal losses of the calf in Chlamydophila-positive herds. Perinatal death and stillbirth are common symptoms in lambs (Papp and Shewen, 1996; Longbottom and Coulter, 2003), but less is known in cattle. However, the observation of increased seroprevalence for Chlamydophila spp. in cows with an abortion history supports the notion that infec-

Table 2. Associations between pregnancy outcomes and presence of Chlamydophila spp. in a study of 100 dairy herds randomly selected in 2007 in western Germany

\begin{tabular}{lrc}
\hline Variable & Positive herds, ${ }^{1} \mathrm{n}_{\text {positive }} / \mathrm{n}_{\text {total }}(\%)$ & Level of significance $\left(\chi^{2}\right.$ test $)$ \\
\hline Abortions ${ }^{2}$ & & $<0.001$ \\
$<2 \%$ & $6 / 34(17.6)$ & \\
2 to $10 \%$ & $21 / 26(80.8)$ & \\
$>10 \%$ & $17 / 18(94.4)$ & $<0.001$ \\
No information & $17 / 22(77.3)$ & \\
Preterm calving $(<270$ d) & $7 / 33(21.2)$ & \\
$<2 \%$ & $16 / 24(66.7)$ & \\
2 to $10 \%$ & $25 / 26(96.2)$ & \\
$>10 \%$ & $13 / 17(76.5)$ & \\
No information & & \\
Perinatal deaths & & \\
$<2 \%$ & $9 / 37(24.3)$ & \\
2 to $10 \%$ & $31 / 41(75.6)$ & \\
$>10 \%$ & $21 / 22(95.5)$ & \\
\hline
\end{tabular}

${ }^{1} \mathrm{~A}$ farm was classified as positive if at least one animal per farm was tested positive for Chlamydophila spp.

${ }^{2}$ The time interval considered was from confirmation of pregnancy to wk 27 of pregnancy. The frequency (\% of cows in the herd) of abortion reports was classified.

${ }^{3}$ Calves that were stillborn after wk 27 of pregnancy or that died within $7 \mathrm{~d}$ after birth. 
Table 3. Associations of the cows' gross appearance and the cleanliness of walkway and beddings with the presence of Chlamydophila spp. in a study of 100 dairy herds randomly selected in 2007 in western Germany

\begin{tabular}{|c|c|c|c|c|c|}
\hline \multirow[b]{2}{*}{ Variable } & \multirow{2}{*}{$\begin{array}{l}\text { Level of significance } \\
\left.\text { ( } \chi^{2} \text { test }\right)\end{array}$} & \multicolumn{4}{|c|}{$\begin{array}{l}\text { Positive herds }{ }^{1} \text { grouped into the } 6 \text {-level classes for } \\
\text { the different variables, } \mathrm{n}_{\text {positive }} / \mathrm{n}_{\text {total }}(\%)\end{array}$} \\
\hline & & Outstanding and good & Average & Fair & Fail and unsatisfactory \\
\hline Feet and legs & $<0.001$ & $6 / 20(30.0)$ & $24 / 44(54.5)$ & $26 / 30(86.7)$ & $5 / 6(83.3)$ \\
\hline Claws & 0.002 & $10 / 30(33.3)$ & $25 / 37(67.6)$ & $24 / 30(80.0)$ & $2 / 3(66.7)$ \\
\hline Joints & $<0.001$ & $7 / 22(31.8)$ & $21 / 39(53.8)$ & $27 / 32(84.4)$ & $6 / 7(85.7)$ \\
\hline Cleanliness of the bedding & $<0.001$ & $12 / 34(35.3)$ & $24 / 40(60.0)$ & $22 / 22(100)$ & $3 / 4(75.0)$ \\
\hline Vaginal cleanliness & $<0.001$ & $12 / 29(41.4)$ & $21 / 41(51.2)$ & $21 / 23(91.3)$ & $7 / 7(100)$ \\
\hline
\end{tabular}

${ }^{1} \mathrm{~A}$ farm was classified as positive if at least one animal per farm was tested positive for Chlamydophila spp.

tion leads to comparable syndromes in cattle, albeit less drastic than in sheep. Wehrend et al. (2005) reported a 6.6-fold higher chance (OR) for abortion in Chlamydophila spp.-seropositive cows. Cavirani et al. (2001) and Wang et al. (2001) also reported an increased frequency of abortions in Chlamydophila spp.-infected cows.

\section{Gross Appearance of the Cows, Barn Characteristics, and Management Practices (Risk Factors)}

Table 3 shows those variables of cow and barn characteristics for which significant differences were established between Chlamydophila spp. positive and negative herds. The scoring system corresponds to the German 6 -level school grading system, with outstanding as the best and unsatisfactory as the lowest possible grade. For the locomotion traits, $>80 \%$ of the positive farms were classified as average and below average. This indicates that Chlamydophila infections may play a role in articular inflammation or damage. It is known that bovine chlamydioses can be associated with polyarthritis (Perez-Martinez and Storz, 1985); in calves with chlamydiosis, enlarged joints that are painful on palpation are reported (Shewen, 1980). Cleanliness of the bedding and walkway, and cow and vaginal cleanliness were also significant for the presence of Chlamydophila spp. More than $80 \%$ of the positive farms failed to have outstanding and good scores for the variables "cleanliness of the bedding," "cleanliness of the cow," and "vaginal cleanliness." For the other variables recorded (cleaning of the watering and feeding places, milking cluster disinfection between individual cows), no relation to Chlamydophila status was found. It should be noted that the result for cluster disinfection is not sufficiently substantiated because only 5 farms in total used it.

Apparently, cleanliness factors play an important role for potential infections with Chlamydophila spp. Fecal shedding by carrier animals and inhalation or ingest- tion of fecal particles represents an important mode of transmission and perpetuation of chlamydioses. Moreover, Chlamydophila spp. can survive in dry feces for months (Perez-Martinez and Storz, 1985). Therefore, the exposure of cows to fecal constituents should be reduced as much as possible, whatever the appropriate measures may be on a given dairy farm.

Considering management practices that might eventually favor the development of Chlamydophila infections in a herd, the source of replacement animals (outside vs. inside), the breeding mode (AI vs. use of breeding bulls), and the calving situation (availability of separate calving pens) were indeed associated with the presence of Chlamydophila spp. (Table 4). The RR for the presence of Chlamydophila spp. in the herd was 2.3-fold higher if replacement of animals was done using external sources. More than $70 \%$ of all positive farms but only $31 \%$ of the negative farms used outside sources for replacement. The conclusion that a herd free of Chlamydophila spp. can minimize the risk for infection by limiting replacement to inside sources is certainly true; nevertheless, this may often not be accomplished by the farms. Therefore, appropriate quarantine measures should be considered when external animals will enter the herd.

Chlamydophila spp. can be transmitted via semen to the female genital tract (Perez-Martinez and Storz, 1985) in many species. In cattle, Chlamydophila spp. may occur in semen from clinically healthy bulls (Bicknell et al., 1986; Teankum et al., 2007), and have also been detected in semen from bulls with seminal vesiculitis (Storz et al., 1968). Cryopreservation will not kill Chlamydophila spp. (Storz et al., 1976), and cows inseminated with infected semen can develop symptoms of chlamydiosis (Storz et al., 1976; Bowen et al., 1978; Appleyard et al., 1985; Rodalkis and Souriau, 1986; Amin et al., 1999). Epidemiologic studies in German bull studs indicate a prevalence (PCR method) of $11 \%$ when semen samples were tested (Kauffold et 
Table 4. Associations between management practices and presence of Chlamydophila spp. in a study of 100 dairy herds randomly selected in 2007 in western Germany

\begin{tabular}{lcccc}
\hline Variable & $\begin{array}{c}\text { Positive herds, } \\
\mathrm{n}_{\text {positive }} / \mathrm{n}_{\text {total }}(\%)\end{array}$ & $P$-value & Risk ratio & $95 \% \mathrm{CI}^{3}$ \\
\hline Replacement animals & & $<0.001$ & 2.344 & $1.428-3.849$ \\
$\quad$ From outside sources & $44 / 56(78.6)$ & & & \\
$\quad \begin{array}{l}\text { From inside sources } \\
\text { Type of insemination }\end{array}$ & $17 / 44(38.6)$ & 0.005 & 2.557 & $1.240-5.276$ \\
Breeding bull & $28 / 35(80.0)$ & & \\
AI & $33 / 65(50.7)$ & \multirow{2}{*}{0.001} & \\
Separate calving pen & $46 / 85(54.1)$ & & \\
$\quad$ Yes & $15 / 15(100)$ & & \\
No & & & \\
\hline
\end{tabular}

${ }^{1} \mathrm{~A}$ farm was classified as positive if at least one animal per farm was tested positive for Chlamydophila spp.

${ }^{2}$ Significance $(P<0.05)$ of $\chi^{2}$ test.

${ }^{3} 95 \% \mathrm{CI}=$ confidence interval of risk ratio.

al., 2007). Given the use of infected males in AI or as breeding bulls, the risk for infecting the females will be limited in case of AI to those animals for which semen of a particular bull is used, whereas the use of a positive breeding bull will affect a higher portion of the entire herd. For our evaluation, we classified those farms that used both AI and natural mating as using breeding bulls. In $82 \%$ of the negative farms, AI was used exclusively; for the positive farms, this proportion was lower $(52.5 \%)$. The calculated 2.5-fold higher $\mathrm{RR}$ for being classified as positive when using breeding bulls confirms the relationships explained above.

During parturition, large numbers of Chlamydophila spp. are shed with fluid discharges and placental membranes and thus form a main source of environmental contamination and transmission to other animals (Papp and Shewen, 1996; Longbottom and Coulter, 2003). From studies in sheep it is known that the number of infections increases if healthy ewes are housed together with ewes that aborted (Blewett et al., 1982). The risk for infection is reduced with separate calving pens because the remaining cows will have fewer chances to be in contact with contaminated materials (Jee et al., 2004). Accordingly, our observation that all farms without separate calving pens were positive for Chlamydophila spp. was not surprising. In this case, $\mathrm{RR}$ could not be calculated because of the use of zero in the cross tabulation. If only one negative tested farm had been observed without a separate calving pen, the calculated RR for positive Chlamydophila spp. classification would be 9.6 (CI: 1.3-69.7). We extended our evaluation by further differentiating the type of calving pens and found that herds with calving pens for individual animals were less likely to be positive for Chlamydophila spp. than those in which animal groups were confined in the calving pens. In $64 \%$ of the positive herds, group calving pens were used, whereas only $33 \%$ of the negative farms used such pens.

\section{CONCLUSIONS}

According to our results, the most promising approaches to minimize the risk for infection and reinfection with Chlamydophila spp. can be condensed to the awareness of those factors identified herein-limit use of replacement from external sources, limit use of breeding bulls, availability of individual calving pens, and keeping the cow environment as clean as possible. Altogether, the factors identified herein support the general hygienic recommendations given to avoid not only chlamydioses but also other infections affecting reproductive health.

\section{ACKNOWLEDGMENTS}

This study was supported by the North RhineWestphalian Ministry of Environment, Conservation, Agriculture and Consumers Protection (MUNLV) within the Inter-Departmental Center of Sustainable Agriculture (USL). We thank K. Sachse from the Federal Research Institute for Animal Health, Institute of Molecular Pathogenesis (Jena, Germany) for imparting to us the details of the PCR methodologies used and for providing the reference standards. We also thank S. Forcob, who then joined our group, for his help with the PCR concerning species identification. The participation of all farmers is gratefully acknowledged.

\section{REFERENCES}

Abd El-Rahim, I. H. A. 2002. Serumuntersuchungen zur Ermittlung der Verbreitung von Chlamydien-Infektionen beim Rind in Nordostdeutschland. Prakt. Tierarzt. 83:268-273.

Amin, A. S., G. M. Darwish, M. S. Ziada, and M. S. Hassan. 1999. Trial to control Chlamydia psittaci in processed buffalo semen. Assiut Vet. Med. J. 40:319-331.

Appleyard, W. T., I. D. Aitken, and I. E. Anderson. 1985. Attempted venereal transmission of Chlamydia psittaci in sheep. Vet. Rec. 116:535-538. 
Arbeitsgemeinschaft Deutscher Rinderzuechter (German Cattle Breeders' Federation). 2006. Rinderproduktion in Deutschland 2005 - Zucht, Besamung, Leistungsprüfung. Arbeitsgemeinschaft Deutscher Rinderzüchter e.V. Druck-Center-Meckenheim, Meckenheim, Germany.

Bicknell, E. J., C. Reggiardo, T. H. Noon, N. Furrey, M. Shupe, M. Mazur, E. A. Le Viness, and R. G. Raciot. 1986. Diagnostic studies on semen from Arizona range bulls. Proc. Am. Assoc. Vet. Lab. Diagnosticians 29:17-24.

Blewett, D. A., F. Gisemba, J. K. Miller, F. W. A. Johnson, and M. J. Clarkson. 1982. Ovine enzootic abortion: The acquisition of infection and consequent abortion within a single lambing season. Vet. Rec. 111:499-501.

Borel, N., E. Kempf, H. Hotzel, E. Schubert, P. Torgerson, P. Slickers, R. Ehricht, T. Tasara, A. Pospischil, and K. Sachse. 2008. Direct identification of chlamydiae from clinical samples using a DNA microarray assay-A validation study. Mol. Cell. Probes 22:5564.

Borel, N., R. Thoma, P. Spaeni, R. Weilenmann, K. Taenkum, E. Brugnera, D. R. Zimmermann, L. Vaughan, and A. Pospischil. 2006. Chlamydia-related abortions in Cattle from Graubunden, Switzerland. Vet. Pathol. 43:702-708.

Bowen, R. A., P. Spears, J. Storz, and G. E. Seidel. 1978. Mechanisms of infertility in genital tract infections due to Chlamydia psittaci transmitted through contaminated semen. J. Infect. Dis. 138:9598.

Buxton, D., R. M. Barlow, J. Finlayson, I. E. Anderson, and A. Mackellar. 1990. Observations on the pathogenesis of Chlamydia psittaci infection of pregnant sheep. J. Comp. Pathol. 102:221237.

Cavirani, S., C. S. Cabassi, G. Donofrio, B. DeIaco, S. Taddei, and C. F. Flamini. 2001. Association between Chlamydia psittaci seropositivity and abortion in Italian dairy cows. Prev. Vet. Med. $32: 259-268$.

DeGraves, F. J., D. Gao, H. R. Hehnen, T. Schlapp, and B. Kaltenboeck. 2003. High sensitivity real-time PCR reveals high prevalence of vaginal infections in cattle. J. Clin. Microbiol. 41:1726-1729.

Domeika, M., A. Ganusaukas, M. Bassiri, G. Froman, and P. A Mardh. 1994. Comparison of polymerase chain reaction, direct immunofluorescence, cell culture and enzyme immunoassay for the detection of Chlamydia psittaci in bull semen. Vet. Microbiol. 42:273-280.

Ehricht, R., P. Slickers, S. Goellner, H. Hotzel, and K. Sachse. 2006. Optimized DNA microarray assay allows detection and genotyping of single PCR-amplifiable target copies. Mol. Cell. Probes 20:6063.

Gerbermann, H. 1991. Chlamydiose beim Rind und ihre Bedeutung im Fruchtbarkeitsgeschehen. Wien. Tieraerztl. Mschr. 78:13-19.

Godin, A.-C., C. Björkmann, S. Englund, K.-E. Johansson, R. Niskanen, and S. Alenius. 2008. Investigation of Chlamydophila spp. in dairy cows with reproductive disorders. Acta Vet. Scand. 50:39.

Goff, J. P., and R. L. Horst. 1997. Physiological changes at parturition and their relationship to metabolic disorders. J. Dairy Sci. 80:1260-1268.

Helps, C., N. Reeves, S. Tasker, and D. Harbour. 2001. Use of realtime quantitative PCR to detect Chlamydophila felis infection. J. Clin. Microbiol. 39:2675-2676.

Hotzel, H., K. Sachse, and H. Pfützner. 1996. Rapid detection of mycoplasma bovis in milk samples and nasal swabs using the PCR. J. Appl. Bacteriol. 80:505-510.

Jee, J. B., F. J. DeGraves, T. Y. Kim, and B. Kaltenboeck. 2004. High prevalence of natural Chlamydophila species infection in calves. J. Clin. Biol. 42:5664-5672.

Kaltenboeck, B., D. Heard, F. J. DeGraves, and N. Schmeer. 1997a. Use of synthetic antigens improves detection by enzyme-linked immunosorbent assay of antibodies against abortigenic Chlamydia psittaci in ruminants. J. Clin. Microbiol. 35:2293-2298.

Kaltenboeck, B., H.-R. Hehnen, and A. Vaglenov. 2005. Bovine Chlamydophila spp. infection: Do we underestimate the impact on fertility? Vet. Res. Commun. 29:1-15.
Kaltenboeck, B., N. Schmeer, and R. Schneider. 1997b. Evidence of numerous omp1 alleles of porcine Chlamydia trachomatis and novel Chlamydia species obtained by PCR. J. Clin. Microbiol. 35:1835-1841.

Kauffold, J., K. Henning, R. Bachmann, H. Hotzel, and F. Melzer. 2007. The prevalence of chlamydiae of bulls from six bull studs in Germany. Anim. Reprod. Sci. 102:111-121.

Laroucau, K., A. Souriau, and A. Rodalkis. 2001. Improved sensitivity of PCR for Chlamydophila using pmp genes. Vet. Microbiol. $82: 155-164$.

Laroucau, K., A. Tricherieau, F. Vorimore, and A. M. Mahe. 2007. A pmp genes-based PCR as a valuable tool for the diagnosis of avian chlamydiosis. Vet. Microbiol. 121:150-157.

Lee, J. K., P. M. van Raden, H. D. Norman, G. R. Wiggand, and T. R. Meinert. 1997. Relationship of yield during early lactation and days open during current lactation with 305-day yield. J. Dairy Sci. $80: 771-776$.

Longbottom, D., and L. J. Coulter. 2003. Animal chlamydioses and zoonotic implications. J. Comp. Pathol. 128:217-244.

Papp, J. R., and P. E. Shewen. 1996. Pregnancy failure following vaginal infection of sheep with Chlamydia psittaci prior to breeding. Infect. Immun. 64:1116-1125.

Perez-Martinez, J. A., and J. Storz. 1985. Chlamydial infections in cattle-Part 1. Mod. Vet. Pract. 66:515-522

Petit, T., J. Spergser, J. Aurich, and R. Rosengarten. 2008. Prevalence of Chlamydiaceae and Mollicutes on the genital mucosa and serological findings in dairy cattle. Vet. Microbiol. 127:325-333.

Reinhold, P., J. Jaeger, E. Liebler-Tenorio, A. Berndt, R. Bachmann, E. Schubert, F. Melzer, M. Elschner, and K. Sachse. 2008. Impact of latent infections with Chlamydophila species in young cattle. Vet. J. 175:202-211.

Rodalkis, A., J. Salinas, and J. Papp. 1998. Recent advances on ovine chlamydial abortion. Vet. Res. 29:276-288.

Rodalkis, A., and A. Souriau. 1986. Response of goats to vaccination with temperature sensitive mutants of Chlamydia psittaci obtained by nitrosoguanidine mutagenesis. Am. J. Vet. Res. 47:26272631.

Sachse, K., and H. Hotzel. 2003. Detection and differentiation of chlamydiae by nested PCR. Methods Mol. Biol. 216:123-136.

Schachter, J., J. Banks, N. Sugg, M. Sung, J. Storz, and K. F. Meyer. 1975. Serotyping of Chlamydia: Isolates of bovine origin. Infect. Immun. 11:904-907.

Shewen, P. E. 1980. Chlamydia infection in animals: A review. Can. Vet. J. 21:2-11.

Sting, R. 1997. Chlamydia psittaci-Infektionen bei Kühen und weiblichen Schafen im nördlichen Baden-Würtemberg. Tierarztl. Umsch. 52:332-339.

Storz, J., E. J. Carrol, L. Ball, and L. C. Faulkner. 1968. Isolation of a psittacosis agent (Chlamydia) from semen and epididymitis of bulls with seminal vesiculitis syndrome. Am. J. Vet. Res. 29:549-555.

Storz, J., E. J. Carroll, E. H. Stephenson, L. Ball, and A. K. Eugster. 1976. Urogenital infection and seminal excretion after inoculation of bulls and rams with Chlamydiae. Am. J. Vet. Res. 37:517520 .

Teankum, K., A. Pospischil, F. Janett, E. Brugnera, L. E. Hoelzle, K. Hoelzle, R. Weilenmann, D. R. Zimmermann, A. Gerber, A. Polkinghorne, and N. Borel. 2007. Prevalence of Chlamydiae in semen and genital tracts of bulls, rams and ducks. Theriogenology 67:303-310.

Wang, F.-I., H. Shich, and Y.-K. Liao. 2001. Prevalence of Chlamydophila abortus infection in domesticated ruminants in Taiwan. J. Vet. Med. Sci. 63:1215-1220.

Wehrend, A., K. Failing, B. Hauser, C. Jäger, and H. Bostedt. 2005. Production, reproductive and metabolic factors associated with chlamydial seropositivity and reproductive tracts antigens in dairy herds with fertility disorders. Theriogenology 63:923-930.

Wilson, M. R., and R. G. Thompsen. 1968. Chlamydia pneumonia of calves. Res. Vet. Sci. 9:467-473.

Wittenbrink, M. M., H. Horchler, and W. Bisping. 1988. Investigation into the incidence of Chlamydia psittaci in the genital tract and feces of female cattle. J. Vet. Med. B 35:237-246. 